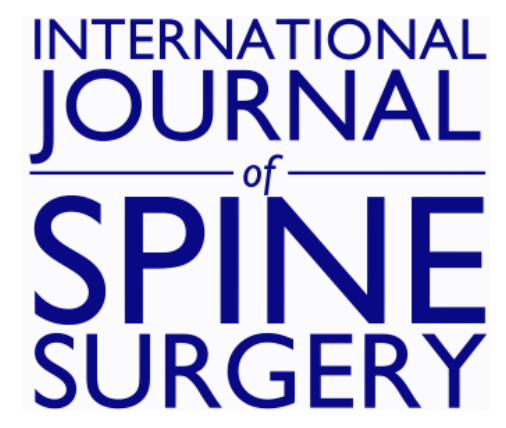

\title{
Spinous Process splitting Laminectomy: Clinical outcome and Radiological analysis of extent of decompression
}

Seungcheol Lee and Umesh Srikantha

Int J Spine Surg 2015, 9 ()

doi: https://doi.org/10.14444/2020

http://ijssurgery.com/content/9/20

This information is current as of April 25, 2023.

Email Alerts Receive free email-alerts when new articles cite this article. Sign up at:

http://ijssurgery.com/alerts

The International Journal of Sdoing Surgehth 2397 Waterbury Circle, Suite 1,

Aurora, IL 60504, Phone: +1-630-375-1432

(C) 2015 ISASS. All Rights Reserved. 


\section{Spinous Process splitting Laminectomy: Clinical outcome and Radiological analysis of extent of decompression}

Seungcheol Lee, M.D., Ph.D, ${ }^{1}$ Umesh Srikantha, M.Ch²

${ }^{1}$ Department of Neurosurgery, Barunsesang Hospital, Seongnam-si, Republic of Korea 2 Department of Neurosurgery, M S Ramaiah Medical Teaching Hospital, Bangalore, India

\section{Abstract}

Introduction

Spinous process splitting laminectomy (SPSL) is a useful technique in achieving adequate decompression for lumbar canal stenosis, has the advantage of simultaneously decompressing multiple levels and minimising injury to the paraspinal muscles. Some concern has been expressed over the efficacy of this technique in decompressing lateral recesses. This study was undertaken to assess the clinical outcome of SPSL technique and radiologically assess the extent of decompression.

Patients and Methods

Thirty-nine consecutive patients treated by SPSL for degenerative lumbar spinal stenosis were methodically assessed for demographic data, clinical findings, Pre- and post-op VAS, JOA scores and spinal canal dimensions on imaging. Surgical technique for SPSL is described.

Results

The mean age of the patients was $66.9 \mathrm{yrs}$. The mean follow-up was 7.3 months. The mean pre- and post-operative VAS scores were 7.8 and 3.7, respectively. The mean pre- and post-operative JOA scores were 6.3 and 11.2, respectively. The mean JOA recovery rate was $57.3 \%$. $77 \%$ of the patients were in the 'good' or 'excellent' McNab's grades at follow-up. Radiologic results were assessed separately at the 118 levels decompressed by the SPSL technique. The ratio increase for the spinal canal dimensions on post-operative images were as follows - Interfacet distance-116.6\%; Effective AP distance-67.6\%; Right lateral recess depth-165.1\%; Right lateral recess angle-145.5\%; Left lateral recess depth-149.3\%; Left lateral recess angle-133.6\%; Cross-sectional spinal canal area-163.8\%. There was no worsening of pre-existing degenerative listhesis or scoliosis in any case.

Conclusion

SPSL achieves effective central and lateral recess decompression, at the same time minimising injury to the paraspinal muscles thus reducing post-operative pain and aiding in quicker mobilisation and recovery. It is an effective tool to treat multiple level spinal stenosis, especially in elderly patients who have pre-existing spinal deformities which can precipitate into frank instability after conventional procedures.

KEYWORDS: SPINOUS PROCESS SPLITTING, LAMINECTOMY, LUMbaR STENOSIS, MULTIPLE LEVEL DECOMPRESSION, PARASPINAL MUSCLE, MiNIMALLY INVASIVE SPINE SURGERY

VOLUME 9 ARTICLE 20 DOI: 10.14444/2020

\section{Introduction}

Lumbar spinal stenosis is the most common degenerative lumbar spine disease and its incidence increases with age. ${ }^{1-3}$ Needless to say, with an increasing old age population in the developed and developing countries, the incidence of elderly patients suffering from symptoms of spinal stenosis has also been on the rise. ${ }^{1,2}$ Conventionally, spinal stenosis has been treated with a standard laminectomy, which includes stripping the paraspinal muscles form their attachment to the spinous process, lamina and sometimes facet joints; removal of the spinous process along with its related ligament complex and laminectomy. Such steps invariably damage the paraspinal, especially multifidus muscle innervations and cause intraoperative ischemic damage to the musculature, resulting in post-operative paraspinal muscle dysfunction which has been speculated as one of the causes of chronic back pain and failed back surgery syn- 
drome. $^{4-8}$

With the advent of minimally invasive surgical techniques, the focus has shifted on maintaining paraspinal muscle function whilst achieving adequate decompression. ${ }^{6}$ These techniques result in lesser blood loss, reduced post-operative pain and quicker recovery. However, using such techniques for decompressing multiple level stenosis, which is more common in the elderly population, increases operative time in this medically and physiologically compromised age group.

Several procedures for preserving paraspinal muscle function while decompressing multiple level stenosis have been described. ${ }^{9-13}$ Watanabe et al. ${ }^{10}$ described a technique of spinous process splitting approach which involves splitting the spinous processes in the midline and preserving the paraspinal muscle attachment to obtain access for laminectomy and decompression. Several concerns have been raised, though, regarding the efficacy of this technique in decompressing the lateral recesses. ${ }^{11,14}$

The purpose of this study was to evaluate the efficacy of this procedure in terms of clinical outcome and assess the radiologic extent of central canal, lateral recess and foraminal decompression.

\section{Patients and Methods}

Thirty-nine consecutive patients who underwent spinous process splitting laminectomy (SPSL) for multi-level lumbar degenerative spinal stenosis in 2010 and 2011 were retrospectively reviewed for demographic data; pre- and postoperativeclinical symptoms and signs; duration of follow-up and intraoperative details. Neurological assessment was done pre-operatively and post-operatively at the time of discharge. VAS scores for back pain were collected pre-operatively and on the first post-operative day. JOA scores (probable scores ranging from -6 to 15) were collected for all patients pre-operatively and at the time of latest follow-up. The JOA scale takes into consideration subjective symptoms (low back pain, leg pain and walking ability), objective findings (Straight leg raising test, sensory disturbance, motor disturbance) and bladder function to assess the scores. JOA recovery rates were calculated according to the Hirabayashi method. ${ }^{11,15}$ The formula to calculate the recovery rate according to this method is \{(PostoperativeJOA score - PreoperativeJOA score)/ (15 - PreoperativeJOA score) $\}$ x 100. McNab's grade of functional improvement for all patients was noted at the time of their last follow-up.

Pre- and postoperativeimaging studies (AP and lateral flexion-extension radiographs; axial CT; Saggital and axial T1W and T2W MRI) were methodically assessed for interfacet distance; effective AP distance; right and left lateral recess depth and angle; crosssectional area of the spinal canal; status of the disc; grade of foraminal stenosis and presence or absence of instability. The criteria for measuring some of the above parameters are described in Table $1^{16}$ and are depicted in Figure 1. Foraminal stenosis was graded according to criteria suggested by Lee et al. ${ }^{17}$ All of the above parameters were assessed independently at each stenosed level for which decompression was done through a split laminar approach. For each lev$\mathrm{el}$, the difference in mean values for the above parameters was calculated. The ratio increase for any parameter at each level was calculated using the following formula - [(Postoperativevalue-

Preoperativevalue)/Preoperativevalue] x 100.

\section{Surgical technique}

All patients underwent the procedure under epidural analgesia supplemented with intravenous sedation. Patients were positioned prone on a wilson's frame and the levels to be decompressed were localised with c-arm guidance. A midline incision was placed extending one level above and one level below the levels to be decompressed and deepened to the tip of the spinous processes. The spinous processes were then longitudinally split in its middle using a high speed $2 \mathrm{~mm}$ diamond burr until its base. Usually this resulted in splitting even the spino-laminar junction to expose the ligamentum flavum. A slightly curved sharp periosteal elevator was then used to carefully dislodge the spinous process base on either side from its laminar junction. This was done as far at the base of the spinous process as possible. Sometimes, when the base of the spinous process is very narrow, drilling in this region usually breaks through the cortex on one side and exposes the corresponding side 
lamina. The contralateral attached part of the spinous process base was then detached from the spinolaminar junction. The portion of the supraspinous ligament bridging the drilled tips of the spinous processes and the intervening interspinous ligaments were divided vertically in the midline using a knife. It was necessary to divide these ligaments superiorly and inferiorly till the adjacent undivided spinous processes to allow for adequate lateral retraction of the split spinous processes. These sequence of steps preserved the attachment of paraspinal muscles to the lateral unexposed part of each half of the spinous process. A weitlaner retractor was then applied and the spinous processes with the attached paraspinal muscles were retracted laterally. During this step the paraspinal muscles were gently elevated from their

\begin{tabular}{|c|c|c|c|}
\hline Parameter & $\begin{array}{l}\text { Imaging } \\
\text { Modality } \\
\text { Sequence }\end{array}$ & $\begin{array}{r}\text { Level where } \\
\text { measured }\end{array}$ & Description \\
\hline $\begin{array}{l}\text { Interfacet } \\
\text { distance }\end{array}$ & $\begin{array}{l}\text { MRI } \\
\text { Axial } \\
\text { T2W }\end{array}$ & $\begin{array}{r}\text { Lower inter- } \\
\text { vertebral } \\
\text { disc }\end{array}$ & $\begin{array}{r}\text { Distance on a line connecting the } \\
\text { medial joint space of facet joints } \\
\text { (post-op) (Fig. 1 B-x') or inner } \\
\text { flaval surfaces along the same line } \\
\text { (pre-op) }{ }^{18} \text { (Fig. } 1 \text { A-x) }\end{array}$ \\
\hline $\begin{array}{l}\text { Effective } \\
\text { AP dis- } \\
\text { tance }\end{array}$ & $\begin{array}{r}\text { MRI } \\
\text { Sag T2W }\end{array}$ & Mid-body & $\begin{array}{l}\text { Distance between a vertical line } \\
\text { connecting the annulus of adjacent } \\
\text { discs and the upper spino-laminar } \\
\text { junction (pre-op) (Fig. 1 G) or the } \\
\text { dorsal dural margin (post-op) (Fig. } \\
1 \mathrm{H} \text { ) }\end{array}$ \\
\hline $\begin{array}{l}\text { Lateral } \\
\text { recess } \\
\text { depth }\end{array}$ & $\begin{array}{l}\text { MRI } \\
\text { Axial } \\
\text { T2W }\end{array}$ & $\begin{array}{r}\text { Lower inter- } \\
\text { vertebral } \\
\text { disc }\end{array}$ & $\begin{array}{r}\text { Distance between the posterior } \\
\text { surface of disc and anteromedial } \\
\text { portion of superior articular } \\
\text { process (post-op) (Fig. 1 B - y' \& } \\
\text { z') or its attached ligamentum } \\
\text { flavum (pre-op) (Fig. } 1 \mathrm{~A}-\mathrm{y} \& \mathrm{z} \text { ) } \\
19\end{array}$ \\
\hline $\begin{array}{l}\text { Lateral } \\
\text { recess an- } \\
\text { gle }\end{array}$ & $\begin{array}{l}\text { MRI } \\
\text { Axial } \\
\text { T2W }\end{array}$ & $\begin{array}{r}\text { Lower inter- } \\
\text { vertebral } \\
\text { disc }\end{array}$ & $\begin{array}{r}\text { Angle between the floor (posterior } \\
\text { disc margin) and roof (anterome- } \\
\text { dial edge of superior articular } \\
\text { process [post-op] (Fig. 1 D) or its } \\
\text { attached ligamentum flavum [pre- } \\
\text { op] (Fig. 1 C)) of the lateral recess } \\
20 *\end{array}$ \\
\hline $\begin{array}{l}\text { Cross- } \\
\text { sectional } \\
\text { area of } \\
\text { the spinal } \\
\text { canal }\end{array}$ & $\begin{array}{l}\text { MRI } \\
\text { Axial } \\
\text { T2W }\end{array}$ & $\begin{array}{r}\text { Lower inter- } \\
\text { vertebral } \\
\text { disc }\end{array}$ & (Fig. 1 E \& F) \\
\hline $\begin{array}{l}\text { Cobb's } \\
\text { angle }\end{array}$ & $\begin{array}{l}\text { AP stand- } \\
\text { ing radi- } \\
\text { ograph }\end{array}$ & & $\begin{array}{l}\text { Angle between the superior end- } \\
\text { plates of the uppermost and lower- } \\
\text { most split laminar levels }\end{array}$ \\
\hline \multicolumn{4}{|c|}{$\begin{array}{l}\text { *modified to be used in MRI to include the effect of posterior annular bulge } \\
\text { and hypertrophied ligamentum flavum on lateral recess angle. MRI - } \\
\text { Magnetic resonance Imaging; AP - Antero-posterior; T1W - T1-weighted } \\
\text { sequence; T2W - T2 weighted sequence. }\end{array}$} \\
\hline
\end{tabular}

laminar attachment laterally upto approximately the middle of facet joints. Use of electrocautery was limited to as minimum as possible. Care was taken to preserve the posterior facet capsule during this manoeuvre. Though on many occasions, it may be difficult to retract the split spinous processes laterally upto the facet complex, elevating the muscles from the joint complex allows medial facetectomy and decompression to be done viewing under the retracted paraspinal muscles.

Decompression was then carried out by the routine steps of laminectomy with or without medial facetectomy and foraminotomy. An operating microscope was usually brought into the field once laminectomy is completed. Under a magnified view, the thickened ligamentum flavum was removed over the central canal and then laterally upto its edge under the articular process. The superior articular process was undercut to decompress the foraminal entry zone. A 2 mm curved kerrison rongeur was then used to complete the foraminotomy. Foraminal decompression was confirmed by passing an oblique probe under the articular process into the foramina. The decompres-

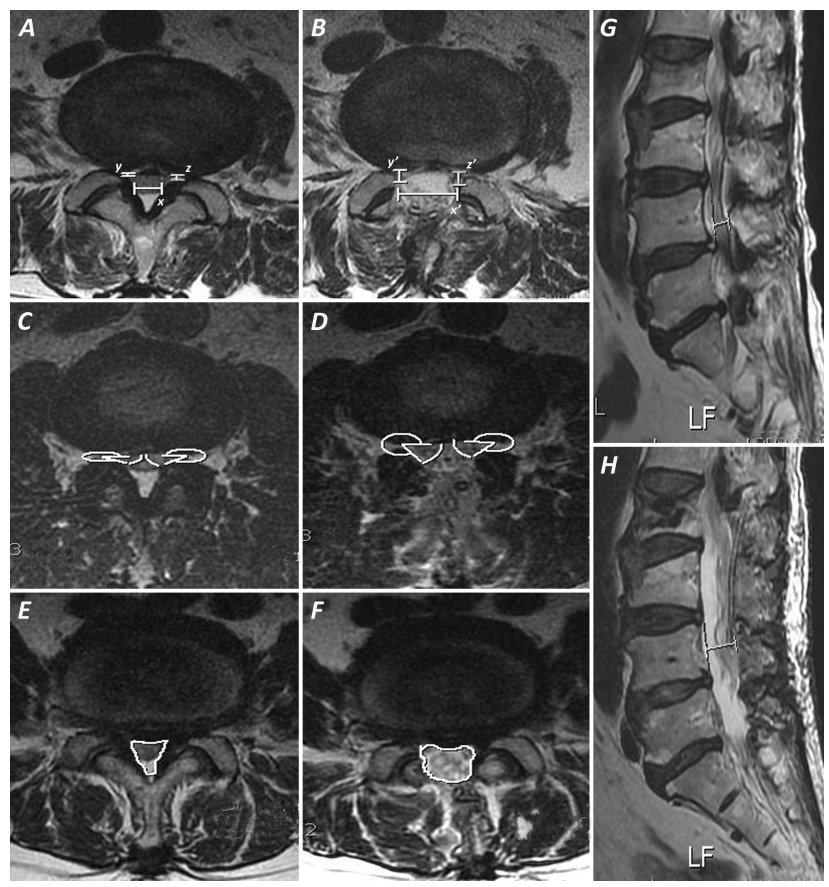

Fig. 1. Images demonstrating the criteria used for measuring spinal canal dimensions in the present study. A \& B - Interfacet distance (A-x - pre-op; $B-x^{\prime}-$ post-op) and lateral recess depth (A-y,z - pre-op; B- $y^{\prime}, z^{\prime}-$ post-op). $C$ E D - Lateral recess angle (C - pre-op; D - post-op). E E F Cross-sectional spinal canal area (E - pre-op; F - post-op). G E H Effective AP canal diameter ( $\mathrm{G}$ - pre-op; $\mathrm{H}$ - post-op) 
sion of the lateral recesses and foramina were aided by adopting an oblique view from the contralateral side and tilting the table and microscope for optimal visualisation. Many patients undergoing this procedure were elderly people with multiple level advanced degenerative changes and usually had associated coronal or saggital plane deformities, though not warranting to be labelled as unstable. Excessive decompression, especially in the region of facet and foramina can precipitate instability which can negate any clinical benefit obtained by decompression. Hence, it is necessary to maintain a balance between adequate posterior elements decompression, symptomatic relief and preserving stability. Additional discectomy was done only if the disc prolapse was $>3 \mathrm{~mm}$ or in the event of persistent lateral recess compression by the disc after posterior decompression.

Once decompression was completed and hemostasis achieved, the spinous processes are re-attached using a non-absorbable suture. It was possible to take a bite through the thinned halves of the spinous processes with a thick needle. The interspinous and supraspinous ligaments in between the split laminae were also re-approximated with intermittent sutures. Patients were mobilised, whenever possible, on the first post-operative day with a soft lumbar support which they were advised to wear for up to 3 weeks.

\section{Results}

The mean age of the 39 patients was $66.9 \mathrm{yrs}$ (37 to 82 yrs; median -69 yrs). There were 14 males and 25 females. The patients had a prolonged duration of symptoms prior to presentation [Mean - 30 months (2 - 120 months)]. Fifty-nine percent (23 patients) had at least one co-morbid illness and $18 \%$ (7 patients) had one major accompanying illness apart from hypertension or diabetes mellitus. The presenting illness was axial back pain in 29 patients (74\%); neurogenic claudication in 24 patients $(61 \%)$ and radicular pain in 24 patients (61\%). Twelve patients (31\%) complained of equivalent bilateral symptoms whereas the rest had symptoms predominantly localised to one side with or without symptoms on the other side. Motor and sensory signs on examination were found in 18 (46\%) and 34 (87\%)patients, respec- tively. Two patients (5\%) had preoperativesphincteric involvement.

One hundred and eighteen stenosed levels were decompressed by spinous process splitting in the 39patients. Of these, 8 patients had 2-level stenosis, 22 patients had 3-level stenosis and 9 patients had 4-level stenosis. The number of split laminar levels in each case was equal to the number of stenosed levels. Of the 118 decompressed levels, 2 were at L 1-2; 19 were at L 2-3; 36 each at L 3-4 and L 4-5 and 25 were at L5-S1. Each of these levels were radiologically analysed individually.

Majority of the levels $(82 / 118 ; 69.5 \%)$ had combined central and lateral canal stenosis. Isolated lateral recess stenosis was observed at 31 levels $(26.3 \%)$ and only a small percentage $(4.2 \% ; 5$ levels) had isolated central stenosis. Diffuse disc bulge contributed to the stenosis at 85 levels $(72 \%)$. Disc prolapse $<3 \mathrm{~mm}$ was noted at 14 levels $(11 \%)$ and prolapse $>3 \mathrm{~mm}$ was noted at 6 levels (5\%). Only disc degeneration without any significant bulge or prolapse was observed at 13 levels (11\%).

The mean duration of surgery was 119 minutes (75 $250 \mathrm{~min}$ ). The mean blood loss was $230 \mathrm{ml}$ (50 - 700 $\mathrm{ml}$ ). Additional discectomy after posterior decompression was required only at 8 levels. Accidental durotomy occurred in 3patients. In all three instances, the dural defect was sutured primarily and closure was supplemented with a fibrin sealant. Two of these patients had post-operative fresh neurological deficits and had a poor overall outcome even at follow-up. There were no postoperativewound complications in any case. Majority of the patients (29 patients; 75\%) were ambulated in a soft lumbar brace on the first post-operative day. The remainder were ambulated on the second or third post-operative day.

The mean duration of follow-up was 7.3 months (2 22 months). The mean pre-operative and postoperative VAS scores were 7.8 and 3.7, respectively. The mean pre-operative and post-operative JOA scores were 6.38 and 11.26 , respectively. Thirty patients (77\%) had made good to excellent recovery according to the McNab's criteria (Table 2). 
The preoperativeand postoperativemean values of all the 118 levels for interfacet distance, effective AP canal diameter, right and left lateral recess depth and angle and cross-sectional spinal canal area are shown in Table 3. The mean postoperativevalues for all parameters were within the normal limits for that particular parameter as described in literature (Figure 2). ${ }^{16}$ This, however, was not true for the lateral recess depth, the normal value for which is $\geq 5 \mathrm{~mm} .{ }^{19}$ However, significant increase was noted in comparison to preoperativevalue. The above parameters were also compared for differences in preoperativeand postoperativevalues among different levels (Table 4). There was almost a proportionate increase in the values for L2-3, L3-4 and L4-5. At L5-S1, a significantly lesser increase in lateral recess depth and lateral recess angle was observed.

Seventy four levels $(62.7 \%)$ were not associated with concomitant foraminal stenosis. At other levels, unilateral and bilateral foraminal stenosis was observed pre-operatively at $29(25 \%)$ and $15(13 \%)$ levels, respectively. Among these 44 levels, Grade 1, Grade 2 and Grade 3 foraminal stenosis were noted at 15, 21 and 8 levels, respectively. The pre- and postoperativecomparison for foraminal decompression is shown in Table 5. In manypatients, there was no sig-

\begin{tabular}{|c|c|c|}
\hline \multirow{2}{*}{ VAS (Back pain) } & Pre-op & $7.8 \pm 1.8(4-10)$ \\
\hline & Post-op & $3.7 \pm 1.3(2-7)$ \\
\hline \multirow{3}{*}{ JOA score } & Pre-op & $6.3 \pm 2.4(-1-11)$ \\
\hline & Post-op & $11.2 \pm 2.6(1-14)$ \\
\hline & $\begin{array}{l}\text { Recovery rate } \\
(\%)\end{array}$ & $\begin{array}{r}57.3 \pm 26.4(-40 \% \text { to } \\
90 \%)\end{array}$ \\
\hline \multirow{4}{*}{$\begin{array}{l}\text { McNab's grade of improve- } \\
\text { ment }\end{array}$} & Excellent & 7 cases $(18 \%)$ \\
\hline & Good & 23 cases $(59 \%)$ \\
\hline & Fair & 7 cases $(18 \%)$ \\
\hline & Poor & 2 cases $(5 \%)$ \\
\hline
\end{tabular}

Values are read as "Mean \pm Standard deviation (Minimum value Maximum value)." VAS - Visual analog scale; JOA - Japanese Orthopaedic Association. nificant difference between the preoperativeand postoperativegrades of foraminal stenosis. Sixty percent of grade $1,52 \%$ of grade 2 and $62 \%$ of grade 3 remained in their same respective grades postoperatively.

Associated degenerative spondylolisthesis was seen at 18 levels. Of these 17 were grade 1 , stable anterolis-

\begin{tabular}{|c|c|c|c|c|c|c|}
\hline \multicolumn{2}{|l|}{$\mathrm{n}=118$} & Pre-op & Post-op & \multicolumn{2}{|c|}{ Difference } & $\begin{array}{l}\text { Ratio in- } \\
\text { crease (\%) }\end{array}$ \\
\hline \multicolumn{2}{|c|}{$\begin{array}{l}\text { Interfacet distance } \\
(\mathrm{mm})\end{array}$} & $\begin{array}{r}9.2 \pm 3.4 \\
(2.8- \\
20.8)\end{array}$ & $\begin{array}{r}17.6 \pm \\
2.0 \\
(11.2- \\
22.1)\end{array}$ & \multicolumn{2}{|c|}{$\begin{array}{r}8.4 \pm 3.1 \\
(0.7-15.8)\end{array}$} & $\begin{array}{r}116.6 \pm \\
83.4 \\
(4.5- \\
564.2)\end{array}$ \\
\hline \multicolumn{2}{|c|}{$\begin{array}{l}\text { AP canal diameter } \\
(\mathbf{m m})\end{array}$} & $\begin{array}{r}9.3 \pm 1.6 \\
(5.8-13.8)\end{array}$ & $\begin{array}{r}15.2 \pm \\
2.0 \\
(11.1- \\
21.0)\end{array}$ & \multicolumn{2}{|c|}{$\begin{array}{r}5.8 \pm 2.3 \\
(1.0-12.3)\end{array}$} & $\begin{array}{r}67.6 \pm 34.4 \\
(8.7- \\
161.8)\end{array}$ \\
\hline \multirow{2}{*}{$\begin{array}{l}\text { Lateral recess } \\
\text { depth } \\
(\mathrm{mm})\end{array}$} & Right & $\begin{array}{r}1.6 \pm \\
0.6 \\
(1.0- \\
4.1)\end{array}$ & \multicolumn{2}{|c|}{$\begin{array}{r}3.9 \pm 1.0 \\
(1.3-6.3)\end{array}$} & $\begin{array}{r}2.3 \pm \\
1.0 \\
(0- \\
5.0)\end{array}$ & $\begin{array}{r}165.1 \pm \\
101.3 \\
(0-500.0)\end{array}$ \\
\hline & Left & $\begin{array}{r}1.7 \pm \\
0.6 \\
(1.0- \\
4.9)\end{array}$ & \multicolumn{2}{|c|}{$\begin{array}{r}3.9 \pm 0.9 \\
(1.7-6.0)\end{array}$} & $\begin{array}{r}2.1 \pm \\
0.9 \\
(-0.7- \\
4.6)\end{array}$ & $\begin{array}{r}149.3 \pm \\
92.1 \\
(-20.0- \\
460.0)\end{array}$ \\
\hline \multirow{2}{*}{$\begin{array}{l}\text { Lateral recess } \\
\text { angle } \\
\left(\text { in }^{\circ}\right)\end{array}$} & Right & $\begin{array}{r}17.6 \pm \\
5.6 \\
(6.7- \\
38.4)\end{array}$ & \multicolumn{2}{|c|}{$\begin{array}{r}39.1 \pm 9.5 \\
(12.4-56.5)\end{array}$} & $\begin{array}{r}21.5 \pm \\
10.6 \\
(0.7- \\
45.4)\end{array}$ & $\begin{array}{r}145.5 \pm \\
103.3 \\
(3.4- \\
422.0)\end{array}$ \\
\hline & Left & $\begin{array}{r}17.9 \pm \\
5.8 \\
(7.2- \\
32.0)\end{array}$ & \multicolumn{2}{|c|}{$\begin{array}{r}37.8 \pm 10.4 \\
(16.6-58.2)\end{array}$} & $\begin{array}{r}19.9 \pm \\
11.1 \\
(0.9- \\
44.9)\end{array}$ & $\begin{array}{r}133.6 \pm \\
106.5 \\
(3.5 \\
\pm 449.0)\end{array}$ \\
\hline $\begin{array}{l}\text { Cross-sectional } \\
\text { area }\left(\mathrm{mm}^{2}\right)\end{array}$ & \multicolumn{2}{|c|}{$\begin{array}{r}80.9 \pm 25.3 \\
(30.6- \\
169.0)\end{array}$} & $\begin{array}{r}194.7 \pm \\
30.2 \\
(114.5- \\
264.2)\end{array}$ & \multicolumn{2}{|c|}{$\begin{array}{r}113.8 \pm 33.8 \\
(18.1- \\
189.1)\end{array}$} & $\begin{array}{r}163.8 \pm \\
90.2 \\
(15.4- \\
412.8)\end{array}$ \\
\hline
\end{tabular}
Maximum value).'

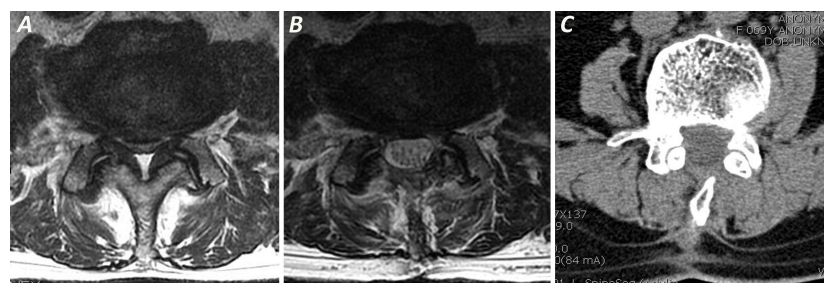

Fig. 2. MR axial T2W images showing severe preoperativecentral and lateral recess stenosis $(A)$ and postoperativeresult after decompression by SPSL technique (B). The preserved spinous process and minimal signal changes in teh paraspinal muscles can be made out. Follow-up CT scan of same case at 3 months showing fusion of the split spinous process (C). 
Table 4. Preoperativeand postoperativecomparison of various spinal canal dimensions among different levels.

\begin{tabular}{|c|c|c|c|c|c|}
\hline & & $\begin{array}{r}\mathbf{L 2 - 3} \\
(\mathrm{n}=19)\end{array}$ & $\begin{array}{r}\mathrm{L3}-4 \\
(\mathrm{n}=36)\end{array}$ & $\begin{array}{r}\text { L4-5 } \\
(n=36)\end{array}$ & $\begin{array}{l}\text { L5-S1 } \\
(n=25)\end{array}$ \\
\hline \multirow{4}{*}{$\begin{array}{l}\text { Interfacet distance } \\
(\mathrm{mm})\end{array}$} & Pre-op & 8.0 & 7.5 & 9.0 & 12.9 \\
\hline & Post-op & 16.0 & 16.9 & 18.4 & 18.9 \\
\hline & Difference & 8.0 & 9.3 & 9.4 & 6.0 \\
\hline & $\begin{array}{l}\text { Ratio increase } \\
(\%)\end{array}$ & 115.8 & 137.0 & 133.6 & 61.6 \\
\hline \multirow{4}{*}{$\begin{array}{l}\text { AP canal diameter } \\
(\mathrm{mm})\end{array}$} & Pre-op & 9.8 & 9.1 & 8.9 & 9.8 \\
\hline & Post-op & 14.8 & 15.0 & 15.4 & 15.5 \\
\hline & Difference & 5.0 & 5.8 & 6.5 & 5.7 \\
\hline & $\begin{array}{l}\text { Ratio increase } \\
(\%)\end{array}$ & 55.3 & 67.7 & 78.0 & 63.6 \\
\hline \multirow{4}{*}{$\begin{array}{l}\text { Right lateral recess } \\
\text { depth } \\
(\mathrm{mm})\end{array}$} & Pre-op & 1.6 & 1.6 & 1.5 & 1.7 \\
\hline & Post-op & 3.9 & 4.0 & 3.9 & 3.9 \\
\hline & Difference & 2.3 & 2.3 & 2.3 & 2.1 \\
\hline & $\begin{array}{l}\text { Ratio increase } \\
(\%)\end{array}$ & 172.2 & 165.0 & 172.8 & 133.0 \\
\hline \multirow{4}{*}{$\begin{array}{l}\text { Left lateral recess } \\
\text { depth } \\
(\mathrm{mm})\end{array}$} & Pre-op & 1.7 & 1.6 & 1.6 & 1.9 \\
\hline & Post-op & 4.2 & 3.8 & 3.9 & 3.5 \\
\hline & Difference & 2.4 & 2.2 & 2.2 & 1.5 \\
\hline & $\begin{array}{l}\text { Ratio increase } \\
(\%)\end{array}$ & 160.9 & 157.8 & 172.5 & 94.4 \\
\hline \multirow{4}{*}{$\begin{array}{l}\text { Right lateral recess } \\
\text { angle } \\
\left({ }^{\circ}\right)\end{array}$} & Pre-op & 18.7 & 16.4 & 16.8 & 19.7 \\
\hline & Post-op & 39.9 & 41.9 & 39.0 & 34.4 \\
\hline & Difference & 21.1 & 25.5 & 22.1 & 14.7 \\
\hline & $\begin{array}{l}\text { Ratio increase } \\
(\%)\end{array}$ & 123.3 & 183.2 & 163.8 & 80.5 \\
\hline \multirow{4}{*}{$\begin{array}{l}\text { Left lateral recess } \\
\text { angle } \\
\left({ }^{\circ}\right)\end{array}$} & Pre-op & 18.9 & 17.4 & 15.3 & 20.8 \\
\hline & Post-op & 37.5 & 39.7 & 36.6 & 36.5 \\
\hline & Difference & 18.5 & 22.2 & 21.3 & 15.6 \\
\hline & $\begin{array}{l}\text { Ratio increase } \\
(\%)\end{array}$ & 112.6 & 152.8 & 159.7 & 87.8 \\
\hline \multirow{4}{*}{$\begin{array}{l}\text { Cross-sectional } \\
\text { canal area } \\
\left(\mathbf{m m}^{2}\right)\end{array}$} & Pre-op & 77.4 & 72.13 & 78.1 & 101.1 \\
\hline & Post-op & 193.2 & 196.3 & 189.5 & 200.7 \\
\hline & Difference & 115.8 & 124.2 & 111.4 & 99.6 \\
\hline & $\begin{array}{l}\text { Ratio increase } \\
(\%)\end{array}$ & 165.6 & 190.6 & 168.5 & 115.5 \\
\hline
\end{tabular}

Values represented are mean values. thesis. Only one patient had a mobile, grade 1 anterolisthesis. This patient was elderly and had severe osteoporosis. Hence, only a decompressive procedure was done. In this patient, as with other cases of stable listhesis, there was no progression of the listhesis at follow-up. Fourteen patients had a preoperative coronal cobb's angle of $>10^{\circ}$ (mean - 16.5; range- 10.1 to 32.3 ). Among these cases, the postoperative angles did not significantly differ from the pre-operative angles (mean - 16.5; range -5.6 to 31.5) (Mean of differences between preoperativeand postoperativeCobb's angle: 0.26 ; range: -5.3 to 4.5 ) (Figure 3).

\section{Discussion}

Several factors are responsible for paraspinal muscle injury during a conventional laminectomy procedure. These include stripping of the muscle from its attachment to the spinous process and lamina, use of electrocautery, damage to the muscle blood supply, forceful retraction, ischemia and denervation injury. ${ }^{4-6,21}$ The multifidus muscle, because of its superior attachment being only to the spinous process and its innervation being derived from the medial branch of dorsal ramus which is susceptible to injury during muscle retraction, is most susceptible to injury during a conventional laminectomy procedure. ${ }^{6,8,21,22}$ Also, removal of spinous processes with ischemic damage of paraspinal muscles resulting in postoperativeatrophy creates a dead space which can facilitate postoperativeinfections and increased area of scar formation dorsal to the dura. ${ }^{8,11,12}$ Such changes have been speculated to be responsible for a significant proportion of patients with post-operative chronic back pain and failed back surgery syn-

Table 5. Comparison of the pre- and postoperative grades of foraminal stenosis.

\begin{tabular}{|c|c|c|c|c|c|}
\hline & & \multicolumn{4}{|c|}{$\begin{array}{r}\text { Postoperative grade of foraminal } \\
\text { stenosis }\end{array}$} \\
\hline & & $\begin{array}{l}\text { Grade } \\
0\end{array}$ & $\begin{array}{r}\text { Grade } \\
1\end{array}$ & Grade 2 & Grade 3 \\
\hline \multirow{3}{*}{$\begin{array}{l}\text { Preoperative grade of } \\
\text { Foraminal stenosis }\end{array}$} & $\begin{array}{r}\text { Grade } 1 \\
(\mathrm{n}=15)\end{array}$ & 6 & $\begin{array}{r}9 \\
(60 \%)\end{array}$ & - & - \\
\hline & $\begin{array}{l}\text { Grade } 2 \\
(\mathrm{n}=21)\end{array}$ & 2 & 8 & $\begin{array}{r}11 \\
(52.4 \%)\end{array}$ & - \\
\hline & $\begin{array}{l}\text { Grade } 3 \\
(\mathrm{n}=8)\end{array}$ & 0 & 0 & 3 & $\begin{array}{r}5 \\
(62.5 \%)\end{array}$ \\
\hline
\end{tabular}


drome. ${ }^{8,11}$ In the SPSL procedure, paraspinal muscle attachment to the spinous process are preserved, compromise of blood supply by cautery or direct vessel coagulation is avoided, retraction induced ischemia and nerve damage is lesser due to the interposing of the divided spinous processes and interspinous ligaments, which serves to act as a mechanical barrier reducing retraction induced pressures in the paraspinal muscles. ${ }^{9-11}$

Watanabe et al. ${ }^{21}$ reported significantly lesser degrees of paraspinal atrophy in SPSL group as compared to the conventional laminectomy group. Cho et al ${ }^{11}$ reported significantly lesser elevations in CPK-MM in SPSL group as compared to conventional laminectomy group. There has been some concern that injury to the supra and interspinous ligament complex is a disadvantage of this approach. ${ }^{14}$ However, since these ligament fibres are oriented longitudinally, splitting and re-attaching them preserves the posterior tension band and does not predispose to the seg-

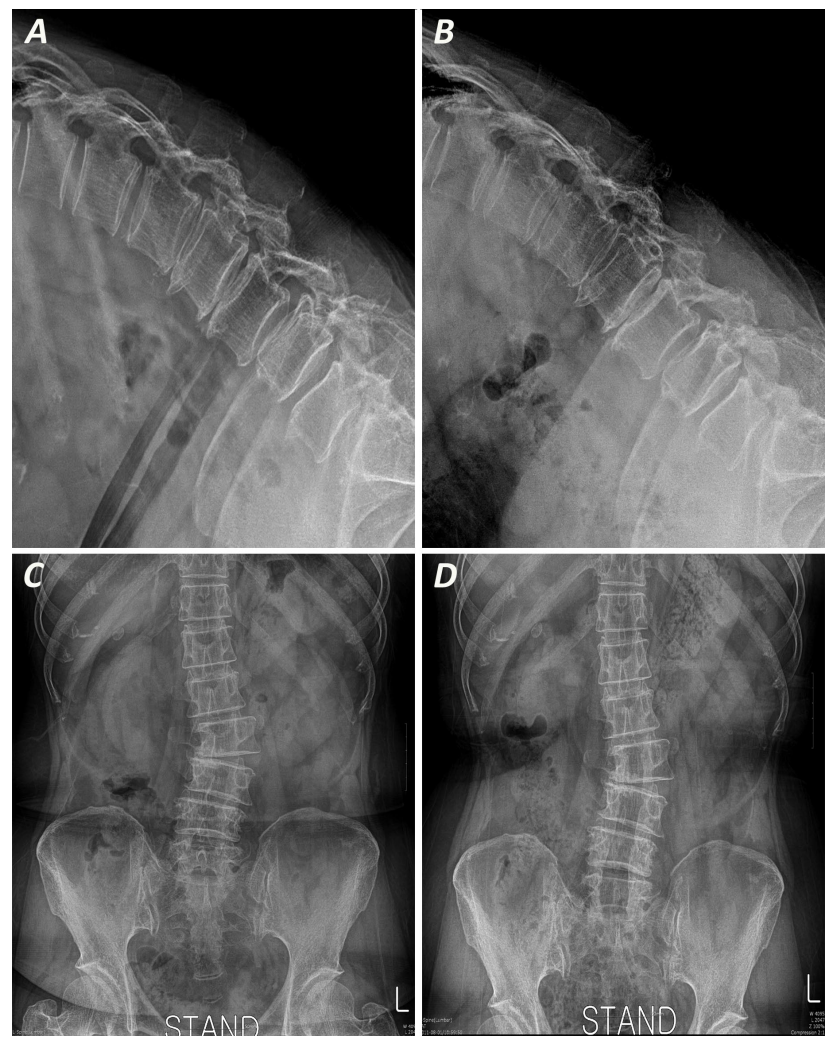

Fig. 3. Radiographs demonstrating safety of SPSL in patients with pre-existing degenerative coronal and saggital plane deformities. A \& B Preoperative(A) and 14 months follow-up (B) standing, lateral flexion radiographs in an illustrative case with two level degenerative listhesis showing no progression at either levels at follow-up. C \& D - Preoperative (C) and 12 months follow-up (D) standing AP radiographs in an illustrative case with degenerative scoliosis showing no progression at follow-up. mental hypermobility often seen after a conventional laminectomy procedure. ${ }^{23}$

Lumbar spinal stenosis is the most common lumbar spine pathology and is the most common indication for a spine surgery after 65 years of age. ${ }^{3}$ The tendency to perform a spine surgery in the elderly is also on the rise ${ }^{1,2}$. The main concern in this age group is that, unlike in the younger population, a larger proportion of patients present with multiple level stenoses. We prefer to do a unilateral approach with bilateral decompression using a tubular retractor for all patients with single or 2-level stenosis. This minimally invasive technique best preserves the paraspinal and ligamentous structure integrity. However, in our experience, adopting this technique for decompressing up to 3 levels results in longer operative time and inadequate lateral canal decompression, especially in between the portals of entry ( $\mathrm{Au}-$ thor's personal experience, unpublished data). Also, in severe facet hypertrophy, ipsilateral lateral recess and foraminal visualisation and decompression will require a larger facet resection, predisposing the spine to instability. SPSL offers a faster and a more effective decompression strategy in suchpatients, the freedom to choose multiple levels of decompression, at the same time preserving spinal stability.

The mean post-operative recovery rate for JOA score in our study is somewhat lower than that reported by other studies. ${ }^{10,11}$ Though the two patients with postoperativecomplication in whom postoperativeJOA scores were significantly lower than preoperativescores might influence the overall lower mean JOA recovery rates, we believe that this could also be due to the larger proportion of patients in the higher age group and a lower mean preoperativeJOA scores as compared to the other series. This could also explain the lower proportion of patients in 'Excellent' $\mathrm{McNab}$ criteria (no restriction of activity) as return to complete normalcy in this elderly set of patients is influenced by several factors other than the outcome of surgery.

Concern has also been expressed over the efficacy of SPSL technique in lateral recess decompression. Incomplete decompression of the lateral recess has been speculated as an important cause for postopera-

Downloaded from http://ijssurgery.com/ by guest on April 25, 2023 
tivepersistent or recurrent leg pain. ${ }^{14}$ Cho et al demonstrated effective central canal and lateral recess decompression using a modification of the SPSL techniques, although they acknowledged the fact that decompression of the lateral recesses might be difficult for a novice neurosurgeon. ${ }^{11}$ In the present study, effective lateral recess decompression was obtained using the original SPSL technique. Though lateral recess depth did not radiologically reach normal values, the observed decompression was effective in relieving symptoms as evidenced by the improvement in JOA scores. Further intra-operative decompression to bring the values closer to the normal range would probably involve additional facet resection and could potentially lead to instability. Another observation in our study was the relatively lesser ratio of increase in lateral recess depth and angle at L5-S1 in comparison to other levels (Table 4). This could probably be because of an anatomically wider canal at L5-S1, thus placing the lateral recesses farther wide apart (also corroborated by higher mean preoperativeinterfacet distance at L5-S1 despite a comparable AP diameter, lateral recess depth and lateral recess angle to other stenosed levels in this series), thus hindering adequate visualisation and limiting the extent of decompression possible through a split spinous approach. As has been previously published, ${ }^{10,11,24}$ we believe that effective lateral recess decompression can be obtained by proper retraction of the paraspinal muscles, changing the lateral tilt of the operating table, and approaching the side of decompression from the contralateral side viewing obliquely under the split lamina and paraspinal muscles. Though, this procedure is not effective for treating foraminal stenosis as noted by the radiologic values in our series, foraminal dissection and freeing of the adhesions around the nerve root in the foraminal area may be responsible for the clinical benefit seen.

The incidence of postoperative (5-10 years) instability after extensive decompressive laminectomy is reported as $3-20 \%$ in various series. ${ }^{7,25,26}$ Elderly patients presenting with spinal stenosis at multiple levels usually also have associated saggital and coronal plane deformities. Multiple level conventional laminectomies in such patients can precipitate postoperative instability which can negate any clinical benefit obtained by decompression. SPSL is an effec- tive option in thesepatients. In the present series, more than a third of patients had a degenerative slip which had not worsened at a mean follow-up period of 7.3 months. Also, pre-existing coronal imbalance did not worsen in any case. Though it would be reasonable to suggest that SPSL prevents degenerative deformity progression in the short term, long term follow-up in a randomised group is necessary to conclusively prove its efficacy over a conventional procedure.

Several surgical techniques have been adopted for preserving paraspinal muscle function whilst achieving adequate decompression in lumbar spinal stenosis. Weiner et al. ${ }^{12}$ reported a spinous process osteotomy technique through a unilateral paraspinal muscle dissection technique that preserved paraspinal muscle attachment on the contralateral side. Watanabe et al. ${ }^{10}$ improvised this technique by splitting the spinous process, preserving bilateral paraspinal muscle integrity and performing a complete laminectomy. Lin et al. ${ }^{24}$ reported a slight modification wherein they preserved the outer one third thickness of the lamina, bent it laterally using an osteotome along with the overlying paraspinal muscles and removed the inner two thirds thickness of the lamina. They minimised paraspinal muscle injury further by preserving their attachment to the laminar surface which was elevated in the original SPSL technique. Cho et al. ${ }^{11}$ used the original spinous process splitting technique, but restricted laminar resection to bilateral laminotomies, rather than a full laminectomy. Hatta et al..$^{13}$ described an interlaminar technique for decompressing single level stenosis by drilling the adjacent portions of the spinous process and splitting the interspinous ligament progressively to expose the interlaminar window. Banczerowski et al. ${ }^{9}$ used a modification of the SPSL technique for spinal tumour resection and described an 'archbone' technique for enlarging the spinal canal diameter by placing a complimentary tricortical iliac crest graft in between the distracted ends of the split spinous processes.

To conclude, SPSL technique offers several advantages over the conventional laminectomy technique. We have demonstrated that it achieves effective central and lateral recess decompression, at the same 
time minimising injury to the paraspinal muscles thus reducing post-operative pain and aiding in quicker mobilisation and recovery. SPSL is an effective tool in treating multiple level spinal stenoses, especially in elderly patients who have pre-existing spinal deformities which can precipitate into frank instability after a conventional procedure. Further longitudinal study will be important in determining efficacy of this procedure.

\section{References}

1. Weinstein JN, Lurie JD, Olson PR, et al. United States' trends and regional variations in lumbar spine surgery:1992-2003. Spine (Phila Pa 1976). 2006;31(23):2707-2714.

2. Deyo, R. A., S. K. Mirza. Trends and variations in the use of spine surgery. Clin Orthop Relat Res. 2006;443:139-146.

3. Katz JN, Harris MB. Clinical practice. Lumbar spinal stenosis. N Engl J Med. 2008;358(8):818-25. 4. Hyun SJ, Kim YB, Kim YS, et al. Postoperative changes in paraspinal muscle volume: comparison between paramedian interfascial and midline approaches for lumbar fusion. J Korean Med Sci. 2007;22(4):646-51.

5. Fan $\mathrm{S}, \mathrm{Hu} \mathrm{Z}, \mathrm{Zhao} \mathrm{F}$, et al. Multifidus muscle changes and clinical effects of one-level posterior lumbar interbody fusion: minimally invasive procedure versus conventional open approach. Eur Spine J. 2010;19(2):316-24.

6. Kim CW. Scientific basis of minimally invasive spine surgery: prevention of multifidus muscle injury during posterior lumbar surgery. Spine 2010;35(26 Suppl):S281-6.

7. Johnson B, Annertz M, Sjoberg C, et al. A progressive and consecutive study of surgically treated lumbar spinal stenosis.Part II; Five year follow-up by an independent observer. Spine (Phila Pa 1976). 1997;22:2938-44.

8. Sihvonen T, Herno A, Paljarva L, et al. Local denervation atrophy of paraspinal muscles in postoperative failed back syndrome. Spine. 1993;18:575-81.

9. Banczerowski P, Vajda J, Veres R. Exploration and decompression of the spinal canal using split laminotomy and its modification, the "archbone" technique. Neurosurgery. 2008;62(5 Suppl
2):ONS432-40.

10. Watanabe K, Hosoya T, Shiraishi T, et al. Lumbar spinous process-splitting laminectomy for lumbar canal stenosis. Technical note. J Neurosurg Spine. 2005;3(5):405-8.

11. Cho DY, Lin HL, Lee WY, et al. Split-spinous process laminotomy and discectomy for degenerative lumbar spinal stenosis: a preliminary report. J Neurosurg Spine. 2007;6(3):229-39.

12. Weiner BK, Fraser RD, Peterson M. Spinous process osteotomies to facilitate lumbar decompressive surgery. Spine (Phila Pa 1976). 1999;24(1):62-6. 13. Hatta $Y$, Shiraishi T, Sakamoto A, et al. Musclepreserving interlaminar decompression for the lumbar spine: a minimally invasive new procedure for lumbar spinal canal stenosis. Spine (Phila Pa 1976). 2009;34(8):E276-80.

14. Lee DY, Lee SH. Spinous process splitting laminectomy for lumbar canal stenosis: a critical appraisal. Minim Invasive Neurosurg.

2008;51(4):204-7.

15. Hirabayashi K, Miyakawa J, Satomi K, et al. Operative results and postoperative progression of ossification among patients with of cervical posterior longitudinal ligament. Spine. 1981;6:354-364. 16. Steurer J, Roner S, Gnannt R, et al, LumbSten Research Collaboration. Quantitative radiologic criteria for the diagnosis of lumbar spinal stenosis: a systematic literature review. BMC Musculoskelet Disord. 2011;12:175.

17. Lee S, Lee JW, Yeon JS, et al. A practical MRI grading system for lumbar foraminal stenosis. Am J Roentgenol. 2010;194:1095-98.

18. Herzog RJ, Kaiser JA, Saal JA, et al. The importance of posterior epidural fat pad in lumbar central canal stenosis. Spine (Phila Pa 1976). 1991;16(6 Suppl):S227-233.

19. Mikhael M, Ciric I, Tarkington J, et al. Neuroradiological evaluation of lateral recess syndrome. Radiology. 1981;140(1):97-107.

20. Strojnik T. Measurement of the lateral recess angle as a possible alternative for evaluation of the lateral recess stenosis on a CT scan. Wien Klin Wochenschr. 2001;113(Suppl 3):53-58.

21. Watanabe K, Matsumoto M, Ikegami T, et al. Reduced postoperative wound pain after lumbar spinous process-splitting laminectomy for lumbar 
canal stenosis: a randomized controlled study. J Neurosurg Spine. 2011;14(1):51-8.

22. See DH, Kraft GH. Electromyography in paraspinal muscles following surgery for root compression. Arch Phys Med Rehab. 1975;56:80-3. 23. Lee MJ, Bransford RJ, Bellabarba C, et al. The effect of bilateral laminotomy versus laminectomy on the motion and stiffness of the human lumbar spine: a biomechanical comparison. Spine (Phila Pa 1976). 2010;35(19):1789-93.

24. Lin SM, Jseng SH, Yang JC, et al. Chimney sublaminal decompression for degenerative lumbar stenosis. J Neurosurg Spine. 2006;4:359-364.

25. Shenkin HA, Hash CJ. Spondylolisthesis after multiple bilateral laminectomies and facetectomies for lumbar spondylosis. Follow-up review. J Neurosurg. 1979;50:45-7.

26. Lee CK. Lumbar spine instability (olisthesis) after extensive posterior spinal decompression. Spine
(Phila Pa 1976). 1983;8:429-3.

\section{Disclosures}

The authors declare no relevant disclosures.

\section{Corresponding Author}

Dr. Seungcheol Lee. MD, PhD, Barunsesang hospital, 69beon-gil 2 Yatap-ro, Bundang-gu, Seongnamsi, Gyeonggi-do, Republic of Korea 463-828. bestspine@gmail.com.

Published 1 June 2015.

This manuscript is generously published free of charge by ISASS, the International Society for the Advancement of Spine Surgery. Copyright @ 2015 ISASS. To see more or order reprints or permissions, see http://ijssurgery.com. 